\title{
TEXTILE-REINFORCED MORTAR EXTERNAL STRENGTHENING OF CORRODED REINFORCED CONCRETE BEAMS
}

\author{
Charles K.S. Moy ${ }^{1 *}$ and Silas Oluwadahunsi ${ }^{2}$ \\ ${ }^{1}$ Lecturer, Department of Civil Engineering, Xi' an Jiaotong-Liverpool University, \\ Suzhou, P.R. China, 215123. Corresponding author: *Email: \\ cloo8000@uni.sydney.edu.au \\ ${ }^{2} \mathrm{PhD}$ Candidate, Department of Civil Engineering, Xi'an Jiaotong-Liverpool \\ University, Suzhou, P.R. China, 215123. Email: silas_e@yahoo.com
}

\begin{abstract}
The need for reliable material techniques for the restoration of corrosion-damaged reinforced concrete (RC) elements cannot be over-emphasised, especially when considering the sustainability aspects of reinforced concrete structures. This investigation examines the application of basalt textile-reinforced mortar for external strengthening of corroded $\mathrm{RC}$ beams in flexure. In that regard, a set of reinforced concrete beams subjected to accelerated corrosion to $10 \%$ and $20 \%$ mass loss of the main steel bars at mid-span and were strengthened using TRM. In total, 7 beams were tested under four-point bending for the following conditions: 1 control, 2 corroded and 4 strengthened. Two strengthening schemes were single ply TRM of equivalent surface area. The results show that corrosion had detrimental effects on load-carrying capacity, yield strength, as well as ductility of corroded beams. Strengthening schemes restored the load capacity of the $10 \%$ corroded beams within a range of $105 \%$ to $112 \%$ of control load capacity. Recovery of the load carrying capacity was not achieved for the $20 \%$ corroded beams. All the strengthened specimens ultimately failed by fibre reinforcement rupture, thus indicating full utilisation of composite action of the TRM.
\end{abstract} Keywords: Reinforced concrete (RC), textile-reinforced mortar (TRM), corrosion, RC beams.

\section{INTRODUCTION}

Corrosion of embedded steel is the leading cause of deterioration of RC elements. Its impact is evidenced by severe losses in strength and stiffness properties, as well as cracks and spalling of concrete cover (Sagues et al, 1997; Poursaee, 2016). Traditionally, epoxy-based fibre reinforcement layers often referred to as fibre- 
reinforced polymers (FRP) were used for repairing and strengthening damaged reinforced concrete members. However, FRP techniques have many drawdacks such as high cost, toxicity, susceptibility to combustion, and poor adhesion of epoxy to concrete substrate (Al-Saidy et al, 2010; El-Maaddawy \& El Refai 2015). For those reasons, cement-based textiles are gradually replacing the use of epoxy-bonded fibres. One example of such cement-based strengthening technique is Textile-reinforced mortar strengthening (TRM) which consists of mortar as the matrix and large mesh size textiles as the strengthening materials. Raoof et al (2017) defined TRM as "a composite comprising high-strength fibres made of carbon, basalt or glass in form of textiles embedded in inorganic materials such as cement-based mortars."

The behaviour of TRM-strengthened beams, in flexure, has been shown to depend on TRM type, repair scheme and number of layers applied (Babaeidarabad et al, 2014; Elghazy et al, 2017). Studies reported in the literature have mostly investigated, and compared FRPs and TRMs in strengthening non-corroded beams, while a few focused on corroded ones (El-Maadawy \& El-Refai, 2015; Elghazy et al, 2017).

Studies on the effectiveness and behaviour of TRMs in strengthening of corroded beams are still lacking. More so, basalt-TRM has not been investigated in the external strengthening (for flexure) of reinforced concrete beams of different degrees of corrosion. Thus, this study presents the outcome of corroded RC beams strengthened externally with basalt-TRM, and tested in flexure under 4-point bending.

\section{EXPERIMENTAL PROGRAMME}

\section{Test Specimens}

In all, 14 specimens were casted, equally split in two groups based on concrete type (normal and high-strength concrete). The mix proportions of the concrete types are shown in Table 1. The average 28th-day compressive strength was $40 \mathrm{~N} / \mathrm{mm}^{2}$ and 51 $\mathrm{N} / \mathrm{mm}^{2}$ for normal (NC) and high strength concrete (HS), respectively. The beam dimension was $130 \mathrm{~mm}$ by $160 \mathrm{~mm}$ by $1200 \mathrm{~mm}$ in length. $10 \mathrm{~mm}$ bars ( 2 Ø10) were used at the top, while $20 \mathrm{~mm} \mathrm{(2} \mathrm{Ø20)} \mathrm{bars} \mathrm{were} \mathrm{used} \mathrm{at} \mathrm{the} \mathrm{bottom.} \mathrm{Links} \mathrm{of} 8 \mathrm{~mm}$ diameter were placed at a spacing of $150 \mathrm{~mm}$ centres in the two shear moment regions (325 mm span); no shear links was placed in the constant moment region $(250 \mathrm{~mm}$ span). The beam reinforcement detail is illustrated in Fig. 1. For each concrete type, there is 1 control, 2 corroded and unrepaired, and 4 corroded and repaired specimens. . 
Table 2 shows the corrosion degree and strengthening scheme of each specimen. An $\mathrm{X}-\mathrm{Y}-\mathrm{Z}$ tagging is used, where $\mathrm{X}$ represents the concrete type (NC or HS); $\mathrm{Y}$ indicates the percentage mass loss of steel and $Z$, the strengthening scheme used.

The textile used for the strengthening was basalt fibre geo-grid type $25 \mathrm{~mm}$ square mesh with a specific surface weight of $350 \mathrm{~g} / \mathrm{m} 3$. The grid is coated with a PVC layer. The mesh has a warp breaking strength and weft breaking strength of $3950 \mathrm{~N} / 50 \mathrm{~mm}$ and $4000 \mathrm{~N} / 50 \mathrm{~mm}$, respectively.

Table 1. Mix Design

\begin{tabular}{lll}
\hline Constituent (kg per m3) & Normal Concrete & High Strength Concrete \\
\hline Cement & 450 & 400 \\
Water & 196.1 & 163.2 \\
Superplasticiser & - & 17.74 \\
Fine Aggregate & 690 & 728.52 \\
Coarse Aggregate $10 \mathrm{~mm}$ & 345 & 467 \\
Coarse aggregate $40 \mathrm{~mm}$ & 690 & 672.48 \\
Silica Fume & - & 100 \\
Steel fibres & - & 30 (Approx. 1.2\%) \\
\hline
\end{tabular}
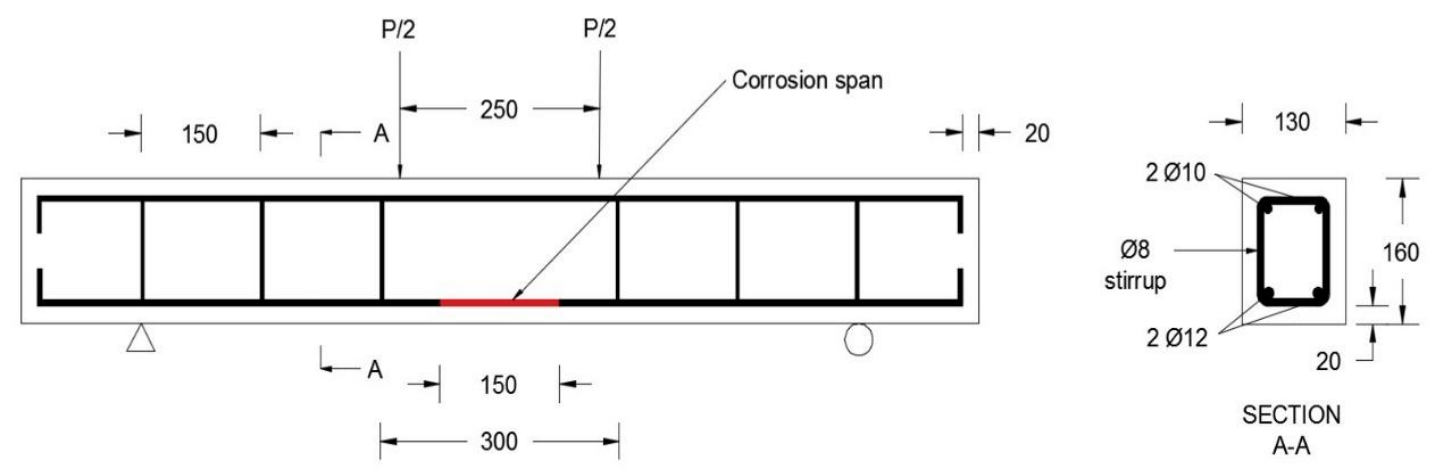

All dimensions are in millimetres

Fig. 1. Steel reinforcement details.

Table 2. Specimen description

\begin{tabular}{|c|c|c|c|c|c|}
\hline Specimen & $\begin{array}{l}\text { Corrosion } \\
\text { (\%) }\end{array}$ & $\begin{array}{l}\text { TRM } \\
\text { scheme }\end{array}$ & Specimen & $\begin{array}{l}\text { Corrosion } \\
\text { (\%) }\end{array}$ & $\begin{array}{l}\text { TRM } \\
\text { scheme }\end{array}$ \\
\hline NC-0 & 0 & none & HS-0 & 0 & none \\
\hline NC-10 & 10 & none & HS-10 & 10 & none \\
\hline NC-10-S1 & 10 & scheme 1 & HS-10-S1 & 10 & scheme 1 \\
\hline $\mathrm{NC}-10-\mathrm{S} 2$ & 10 & scheme2 & HS-10-S2 & 10 & scheme2 \\
\hline
\end{tabular}




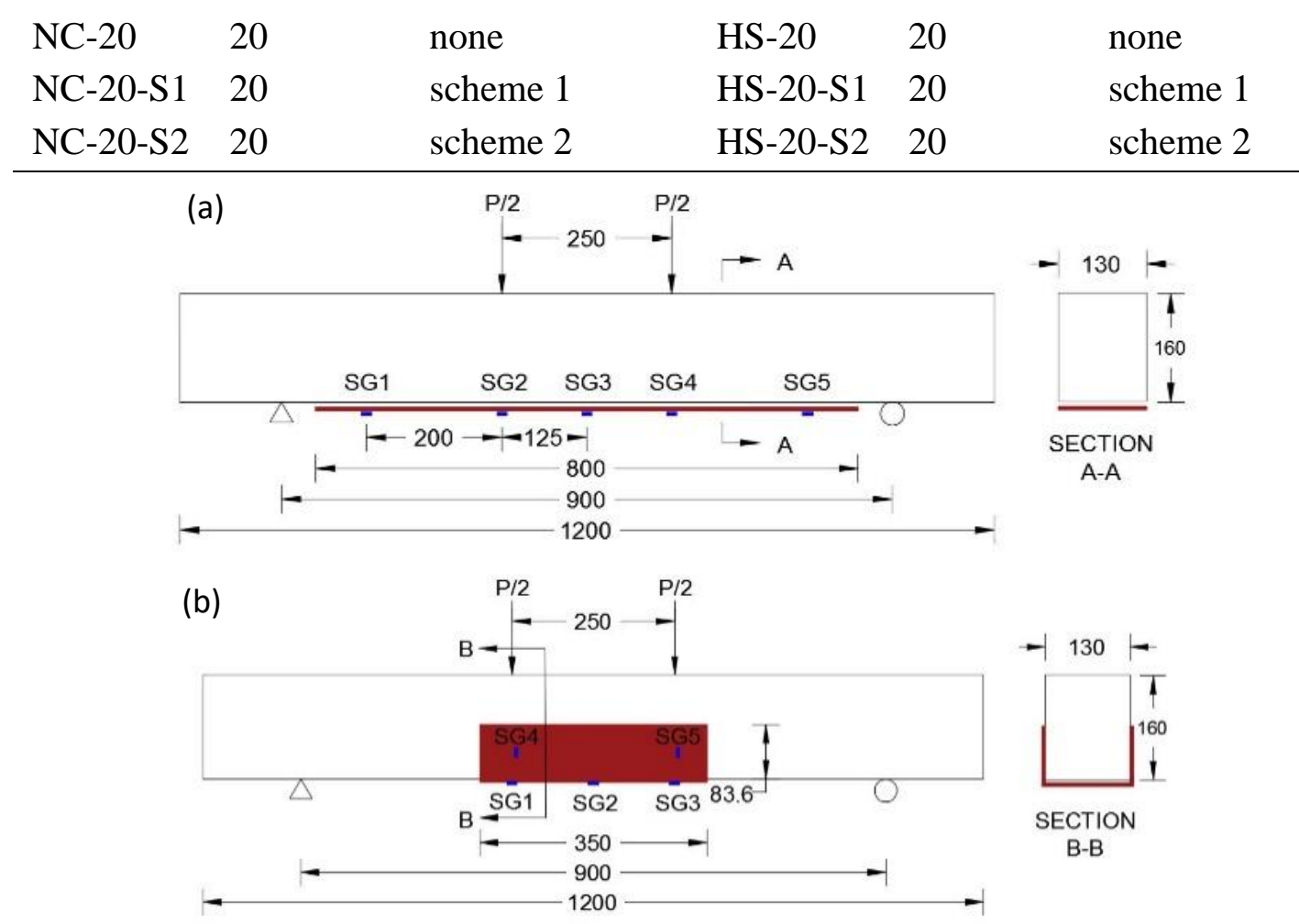

Fig. 2. Basalt-TRM strengthening scheme (a) laminate (b) U-Wrap.

\section{Accelerated Corrosion}

In inducing corrosion in specimens, constant current of $250 \mu \mathrm{A}$ was impressed in tension reinforcement with duration $(\mathrm{t})$, as presented in Table 3, for the respective mass losses. The duration was determined using equation (1). Only a length of $150 \mathrm{~mm}$ at mid-span was subjected to the process, as other parts of the steel cage were epoxycoated. The electrolyte used is saltwater solution of $4 \% \mathrm{NaCl}$ concentration by mass.

$$
t=\frac{m z F}{I M}
$$

Table 3. Accelerated Corrosion Aging

\begin{tabular}{lll}
\hline Corrosion rate $(\boldsymbol{\%})$ & $\mathbf{1 0}$ & $\mathbf{2 0}$ \\
\hline Mass of rebar exposed to corrosion $(\mathrm{g})$ & 133.172 & 133.172 \\
Length exposed 1 (mm) & 150 & 150 \\
Equivalent Mass loss (m) (g) & 13.3172 & 26.6344 \\
Applied current I (A) & 0.25 & 0.25 \\
Molar Mass of steel (M) (g/mol) & 55.847 & 55.847 \\
Valency Fez+ (z) & 2 & 2
\end{tabular}


Faraday Constant (F) (C/mol)

Time (t) (sec)
96487

184065.4
96487

368130.9

\section{Strengthening Schemes and Application}

Both strengthening schemes cover an equivalent area on the corroded specimens. Prior to the application of the TRM, the concrete cover over the corroded steel was removed, the bars cleaned and covered with fresh concrete. The surfaces to apply the schemes to (soffit and sides) were prepared by cutting grooves of approx.1.5 $\mathrm{mm}$ depth and width using a grinder (see Fig. 3). The surfaces were kept moist for over 24 hours before the application of the mortar in order to prevent early shrinkage in mortar.

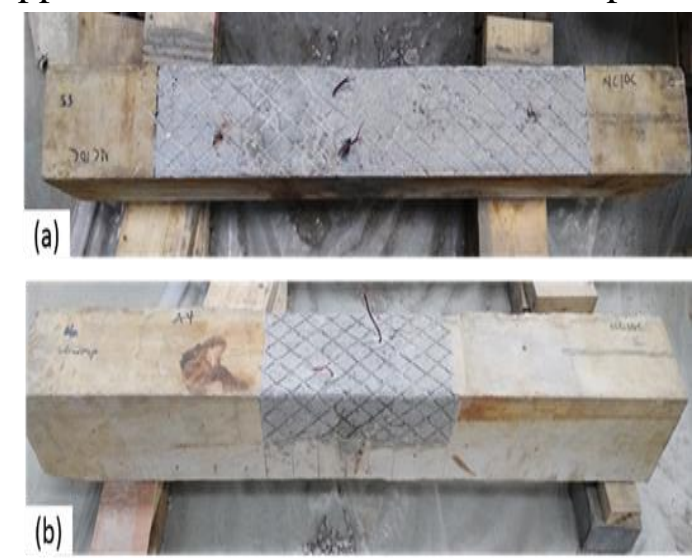

Fig. 3. Surface preparation (a) scheme 1 (b) scheme 2 .
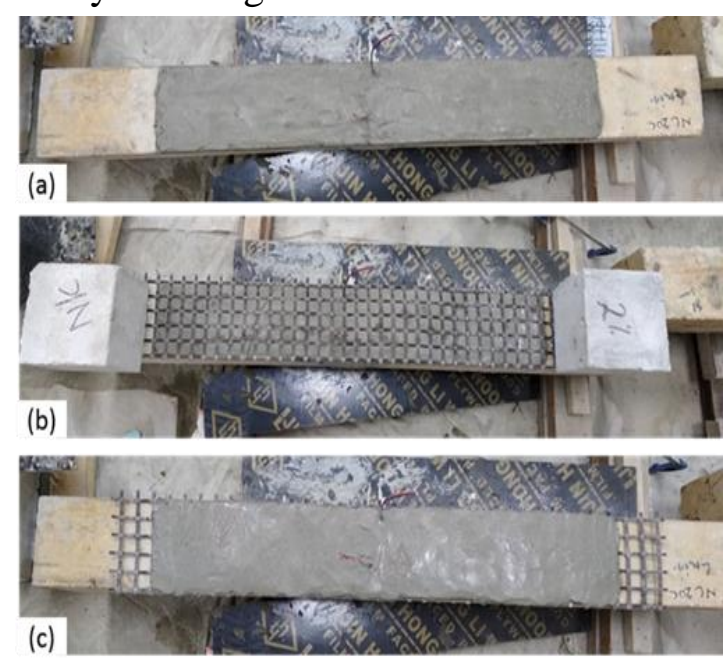

Fig. 4. TRM Application (a) First mortar layer (b) impression of textile into mortar (c) final mortar layer applied.

\section{Testing and Instrumentation}

A $300 \mathrm{kN}$ Universal Testing Machine (UTM) was used in testing the beams to failure

in a four-point bend setup (see

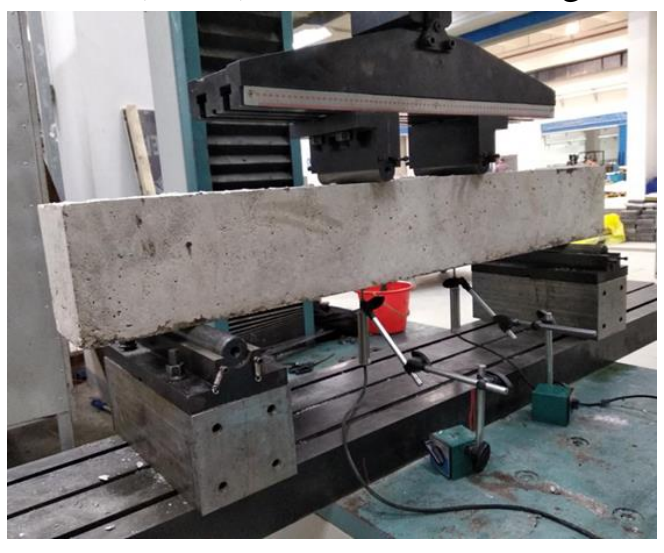


Fig. 5). Displacement rate was set at $1 \mathrm{~mm} / \mathrm{min}$. Clear span between supports was 900 $\mathrm{mm}$ while the loading pins were at $250 \mathrm{~mm}$ centres. Two linear variable displacement traducers (LVDT) were placed at the bottom of the beams, to measure displacement.

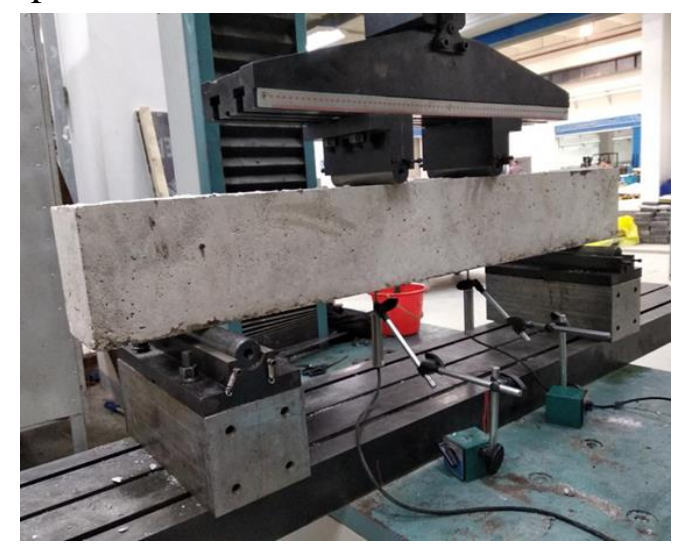

Fig. 5. Loading Setup.

\section{RESULTS AND DISCUSSION}

Table 4. Strength and Ductility result

\begin{tabular}{|c|c|c|c|c|c|}
\hline \multirow[t]{2}{*}{ Specimen } & \multicolumn{2}{|c|}{ Load values } & \multicolumn{2}{|c|}{ Deflection values } & \multirow{2}{*}{$\frac{\text { Ductility Index }}{\delta_{\mathrm{u}} / \delta_{\mathrm{y}}}$} \\
\hline & $\mathbf{P}_{\mathbf{y}}(\mathbf{k N})$ & $\mathbf{P}_{\mathrm{u}}(\mathbf{k N})$ & $\delta_{\mathbf{y}}(\mathbf{m m})$ & $\boldsymbol{\delta}_{\mathbf{u}}(\mathbf{m m})$ & \\
\hline NC-0 & 91.6 & 106.5 & 6.7 & 19.7 & 2.94 \\
\hline NC-10 & 54.8 & 94.8 & 4.3 & 11.9 & 2.77 \\
\hline NC-10-S1 & 59.2 & 119 & 3.6 & 11.7 & 3.25 \\
\hline NC-10-S2 & 70.5 & 100 & 3.6 & 9.2 & 2.56 \\
\hline NC-20 & 50 & 83 & 3.1 & 9.1 & 2.94 \\
\hline NC-20-S1 & 50.1 & 89.2 & 3.2 & 8.0 & 2.50 \\
\hline NC-20-S2 & 51.6 & 88.8 & 3.0 & 8.8 & 2.93 \\
\hline HS-0 & 107.1 & 111.0 & 6.2 & 24.3 & 3.92 \\
\hline HS-10 & 57 & 100 & 4.3 & 14.9 & 3.47 \\
\hline HS-10-S1 & 71.6 & 110.6 & 3.59 & 7.61 & 2.12 \\
\hline HS-10-S2 & 83 & 115.7 & 5.3 & 13.7 & 2.58 \\
\hline HS-20 & 55.9 & 82.6 & 3.6 & 9.7 & 2.69 \\
\hline HS-20-S1 & 59.8 & 87 & 3.7 & 7.95 & 2.15 \\
\hline HS-20-S2 & 58.5 & 89 & 3.7 & 8.8 & 2.38 \\
\hline
\end{tabular}

\section{Strength Analysis}

Experiment results are presented in Table 4. It summarizes strength and ductility results of tested beam specimens. Ductility index is the ratio of mid-span deflection at specimen's ultimate load to that of yield load. $10 \%$ corrosion at mid-span resulted in 
an $11 \%$ reduction in ultimate load in NC-10 and $9.9 \%$ in HS-10 specimens. $20 \%$ corrosion caused $22 \%$ and $26 \%$ reduction in ultimate load of NC-20 and HS-20, respectively.

\section{Scheme 1}

Specimen NC-10-S1 increased by $26 \%$ in peak load, which is a $112 \%$ restoration with respect to the control specimen, NC-0. HS-10-S1 gained 10.6\%, an approximate restoration to original strength. NC-20-S1 and $\mathrm{HS}-20-\mathrm{S} 1$ gained $7.5 \%$ and $5.3 \%$, respectively. Therefore, the scheme could only restore $10 \%$ corroded specimens to original ultimate load. In yield strength, NC-10-S1 and HS-10-S1 gained 8\% and 25.6\%, respectively. NC-20-S1 and HS-20-S1 increased in yield load by $0.2 \%$ and $7 \%$, respectively.

\section{Scheme 2}

NC-10-S2 had an increment of $26 \%$, HS-10-S2 by $15.4 \%$, NC-20-S2 added $9.4 \%$ while HS-20-S2 had 10\% gain. In yield load performance, NC-10-S2 gained 10\%, while HS10-S2 and NC-20-S2 added 55.5\% and 20\%, respectively. HS-20-S2, however, had a decrement of $8 \%$. In ductility index, Scheme 2 reduced that of NC-10-S2 and HS-10S2 by $23 \%$ and $32 \%$, respectively. NC-20-S2 increased by $16 \%$ while HS-20-S2 reduced by $8 \%$. The scheme restored NS-10-S2 to $112 \%$ of the non-corroded peak load and $104 \%$ of the yield load. HS-10-S2 surpassed initial peak load by $10 \%$ while yield load was not restored.

\section{Load-Deflection Behaviour}

Fig. 6(a) shows that NC-10-S1 gained higher strength increase compared to NC-10-S2, which only increased in load capacity, but was not restored to original strength. However, the latter exhibited better ductility. In 10\% corroded high strength beams (See

Fig. 6 (b)), HS-10-S2 had a superior load increase and ductility performance, similar to that of the control specimen, in comparison to HS-10-S1. In

Fig. 6(c) and (d), high strength beams strengthened with both schemes showed higher ductile behaviour compared to normal concrete beams. However, none of these beams ( $20 \%$ corroded) was restored to original strength and ductile behaviour. 


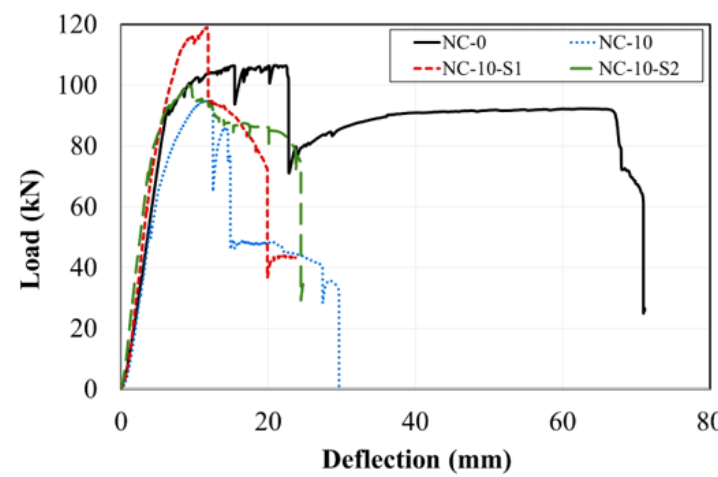

(a)

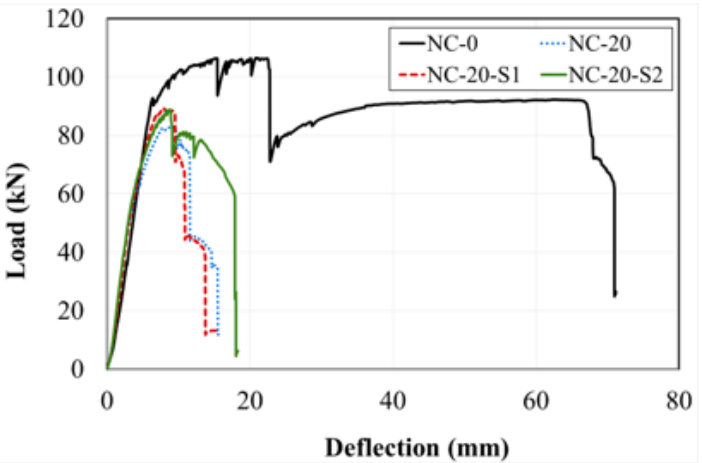

(c)

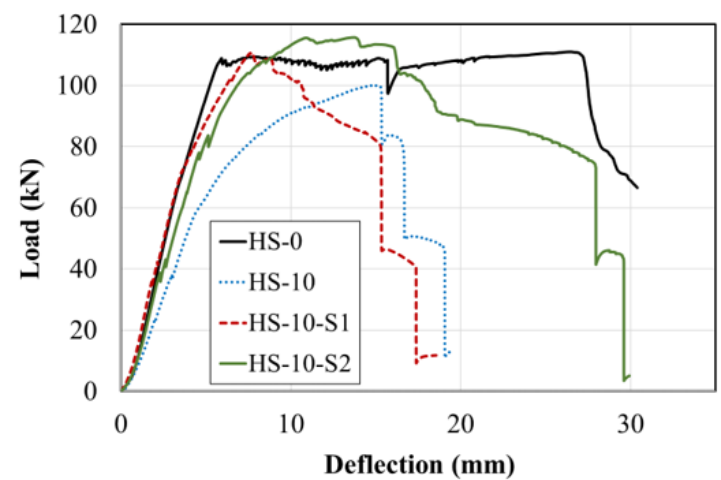

(b)

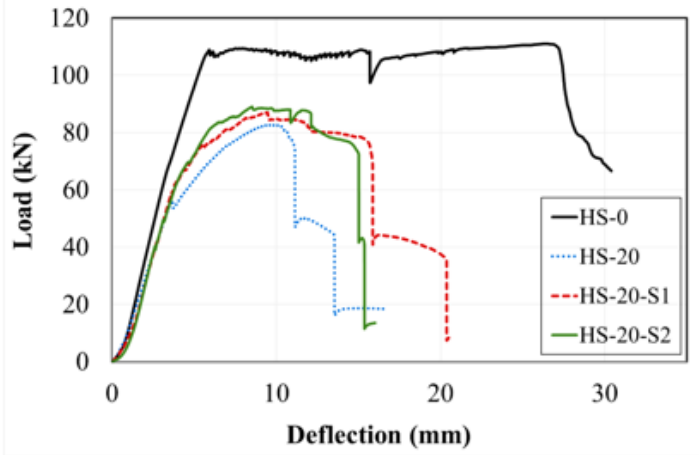

(d)

Fig. 6. Load-deflection plots (a) 10\% corroded NC beams (b) $10 \%$ corroded HS beams (c) $20 \%$ corroded NC beams (d) $20 \%$ corroded HS beams.

\section{Failure Mode}

The failure of all beams tested starting with yielding of tension steel reinforcement and subsequent compression crushing of concrete at the loading points. Moreover, the ultimate failure mode observed in all strengthened specimens is fibre rupture. This is depicted in Fig. 7 showing failure of representative specimens (HS-10-S1 and HS-10S2).

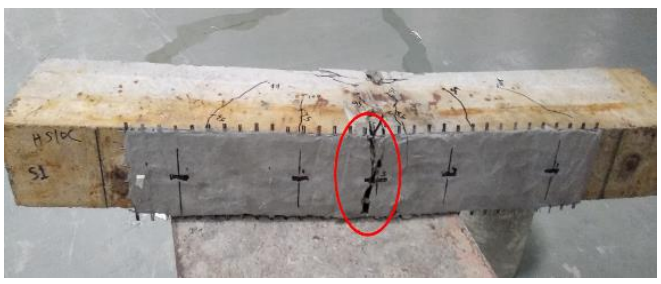

(a)

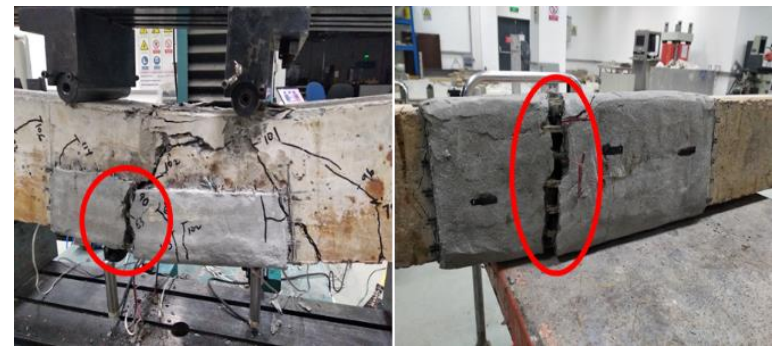

(b)

Fig. 7. Failure modes (a) Scheme 1 (b) Scheme 2. 


\section{CONCLUSION}

In this study, corroded beams of $10 \%$ and $20 \%$ steel mass losses (at mid-span) were strengthened using with two schemes of single ply basalt-TRM. A total of 14 beams were tested in flexure, with 8 corroded and strengthened with single ply basalt-TRM. From the test results, the following conclusions are drawn:

- $10 \%$ corrosion led to similar peak load loss in NC and HS concrete beams, $11 \%$ and $9.9 \%$ respectively. Doubling the steel mass losses led to $22 \%$ and $25.6 \%$ strength losses in the aforementioned beams, respectively.

- Both strengthening schemes restored 10\% corroded beams to and beyond control beam peak loads, with the exception of Scheme 2 in NC-10-S2. However, the converse was the case with $20 \%$ corroded ones.

- Increment in load-carrying capacity of corroded beams was increased within a range of $5.3 \%$ to $26 \%$. Yield load and ductility index were improved but was not always the case.

- Overall, U-Wrap scheme provided the higher peak load and load-deflection response recovery, especially with high strength concrete.

- The only failure mode observed in strengthened specimens is textile rupture, which implies a full utilization of TRM composite in specimens.

\section{REFERENCES}

Babaeidarabad, S., Loreto, G. and Nanni, A., 2014. Flexural strengthening of RC beams externally bonded fabric-reinforced cementitious matrix. Journal of Composites for Construction, 18(5), p.04014009.

Elghazy, M., El Refai, A., Ebead, U. and Nanni, A., 2017. Corrosion-damaged reinforced concrete beams repaired with fabric-reinforced cementitious matrix (FRCM). J Compos Constr nd.

El-Maaddawy, T. and El Refai, A., 2015. Innovative repair of severely corroded Tbeams using fabric-reinforced cementitious matrix. Journal of Composites for Construction, 20(3), p.04015073.

Raoof, S.M., Koutas, L.N. and Bournas, D.A., 2017. Textile-reinforced mortar (TRM) versus fibre-reinforced polymers (FRP) in flexural strengthening of RC beams. Construction and Building Materials, 151, pp.279-291.

Sagues, A.A., Moreno, E.I., Morris, W. and Andrade, C., 1997. Carbonation in concrete and effect on steel corrosion (No. WPI 0510685,). 